\title{
MODAIS ALTERNATIVOS DE PASSAGEIROS
}

\author{
ALTERNATIVE PASSENGER MODELS
}

\section{Olivia Fadin Camargo \\ Acadêmica do curso de Engenharia de Agrimensura, UNESC. E-mail: oliviafcamargo@gmail.com}

Paula Miranda Rosso

Acadêmica do curso de Engenharia de Agrimensura, UNESC. E-mail: paulamrosso@hotmail.com

Nilzo Ivo Ladwig

Universidade do Extremo Sul Catarinense - UNESC. E-mail: ladwig@unesc.net

\section{RESUMO}

Neste trabalho, foi apresentada uma pesquisa exploratória sobre os modais alternativos de transporte disponíveis para a população, assim como ideias e exemplos para que os grandes centros urbanos consigam integrar os modais e ampliar a visão para a mobilidade urbana sustentável. A metodologia usada seguiu uma abordagem qualitativa, por meio de pesquisas bibliográficas em livros, artigos e websites, em que foram encontrados exemplos de tecnologias que podem ajudar as cidades a trazer mais sustentabilidade para a mobilidade. Além disso, foi feita uma pesquisa de campo, com 49 pessoas, visando examinar a opinião das pessoas sobre o uso dos transportes nas cidades e como torná-los mais sustentáveis.

Palavras-chave: Transportes. Mobilidade. Trânsito. Sustentabilidade. Infraestrutura.

\section{ABSTRACT}

The study followed an exploratory investigation aiming to examine the existing alternatives and more sustainable passenger transport modes. Moreover, examples of these modes was presented and ideas was discussed in order to show possibilities for integrating the transport modes in the urban centres that could improve mobility and seek to sustainability. The methodology was based on bibliography as papers and websites, used to search for examples of technologies for sustainable mobility. Furthermore, it was conducted a survey with 49 people, to examine their opinions about transport use in cities and to make them more sustainable.

Keywords: Transports. Mobility. Traffic. Sustainability. Infrastructure. 


\section{INTRODUÇÃO}

Durante anos, a humanidade ocupou os diferentes espaços geográficos e sentiu necessidade de se locomover mais rápido e viajar longas distâncias. Atualmente, com a evolução de inúmeras tecnologias, esses desejos se tornaram possíveis. Todas essas invenções e tecnologias vieram para melhorar e facilitar nossas vidas, principalmente nos grandes centros urbanos. Porém, surgiram outros problemas. Com o aumento da utilização dos meios de transportes motorizados, o trânsito das cidades vem se tornando caótico, impossibilitando uma movimentação segura e eficiente. Neste trabalho, apresentaremos os diversos problemas que enfrentamos ao nos locomovermos e demonstraremos as vantagens de se usar meios de transportes alternativos a veículos, bem como as soluções encontradas pelo governo de melhorar a situação confusa em que se tornou o trânsito das cidades.

\section{MODAIS ALTERNATIVOS DE TRANSPORTES DE PASSAGEIROS E CARGAS}

O principal meio de transporte utilizado hoje são os automóveis. Não podemos negar que eles nos trazem algumas vantagens pessoais, como melhor acessibilidade, conforto, privacidade e intimidade. Porém, se prestarmos atenção e andarmos de carro por alguns minutos em algum centro de cidade, principalmente nos horários do começo e final do dia, vamos perceber a dificuldade de se locomovermos de carro. A ideia inicial de ter um veiculo próprio se perde e começamos a ver as desvantagens de tantos carros sendo utilizados ao mesmo tempo. Claro que não é errado ter um veículo próprio, mas podemos avaliar a real necessidade de usarmos um carro sozinho ou outras opções mais sustentáveis sem que sobrecarreguemos o trânsito das cidades.

Diante da situação acima, a busca pelo desenvolvimento sustentável tem sido um dos assuntos mais discutidos ao se planejar o meio urbano. Dentre os principais motivos, estão o crescimento desordenado das cidades e espalhamento diante da incapacidade do governo público de controlar a expansão territorial; degradação ambiental e falta de áreas verdes por causa da grande poluição e desmatamento; desigualdade social; descontinuidade de ações e investimentos nessas áreas; falta de integração e qualidade dos transportes. Apesar desses problemas, observa-se um crescimento de pesquisas e aplicações, principalmente no âmbito federal com a criação do Ministério das Cidades, em 2003, e internacionalmente, com diversos experimentos sendo colocados em prática.

\section{EVOLUÇÃO DOS MEIOS DE TRANSPORTES}


O homem sempre sentiu necessidade de se transportar de um lugar para outro. Durante milhares de anos, o principal meio de se locomover era a pé. Logo depois, apareceu o primeiro transporte, uma jangada que ainda na Pré-História ajudava o homem a conseguir seu alimento através da pesca. Há 5500 anos, surgia a invenção das rodas, possibilitando o uso de animais e a invenção das carroças para transportar pessoas e cargas. No século XV, Leonardo Da Vinci inventou a bicicleta, sendo hoje ainda amplamente utilizada. Pode-se destacar outras invenções ao longo dos anos:

a) surgimento do barco a vapor (1807): a máquina a vapor foi essencial para muitos meios de transportes, especialmente os navios. O primeiro barco a vapor bemsucedido foi inaugurado pelo americano Robert Fulton e Ra chamado de Clermont. Dentro do transporte marítimo, o vapor era capaz de movimentar essas máquinas pelos oceanos;

b) surgimento do transporte ferroviário (1830): o transporte ferroviário tornou-se popular a partir de 1830, e um dos principais inventores foi George Stephenson, criador da locomotiva a vapor;

c) invenção do automóvel moderno (1886): o alemão Karl Benz foi o responsável pela criação do primeiro automóvel de três rodas movido à gasolina;

d) surgimento da aviação comercial (1926): o avião abriu a nova fase de revolução nos transportes e sua criação é atribuída a três pessoas, os irmãos americanos Wilbur e Orville Wright (1903) e Santos Dumont (1906). Com esse meio de transporte, a população não precisa mais utilizar apenas os navios para fazer longas viagens;

e) início do transporte espacial (1926): o transporte espacial começou a ser introduzido pelo americano Robert H. Gooddard, criador dos primeiros foguetes de combustível líquido.

\section{PRINCIPAIS MEIOS DE TRANSPORTES ALTERNATIVOS ENCONTRADOS}

\section{VEICULO LEVE SOBRE TRILHOS (VLT)}

O veículo leve sobre trilhos (VLT) surgiu em diversas cidades pelo mundo, sistema esse alimentado por energia elétrica garantindo a redução de poluição tanto por emissão de gases quanto pela poluição sonora, já que o transporte é silencioso, além da flexibilidade na mobilidade urbana. Atualmente, a cidade do Rio de Janeiro utiliza esse recurso, tendo sido um dos investimentos feitos pelo governo municipal para os Jogos Olímpicos 2016. As cidades de São Paulo, Santos e São Luis dispõem desse serviço. 
Figura 1 - VLT no Rio de Janeiro

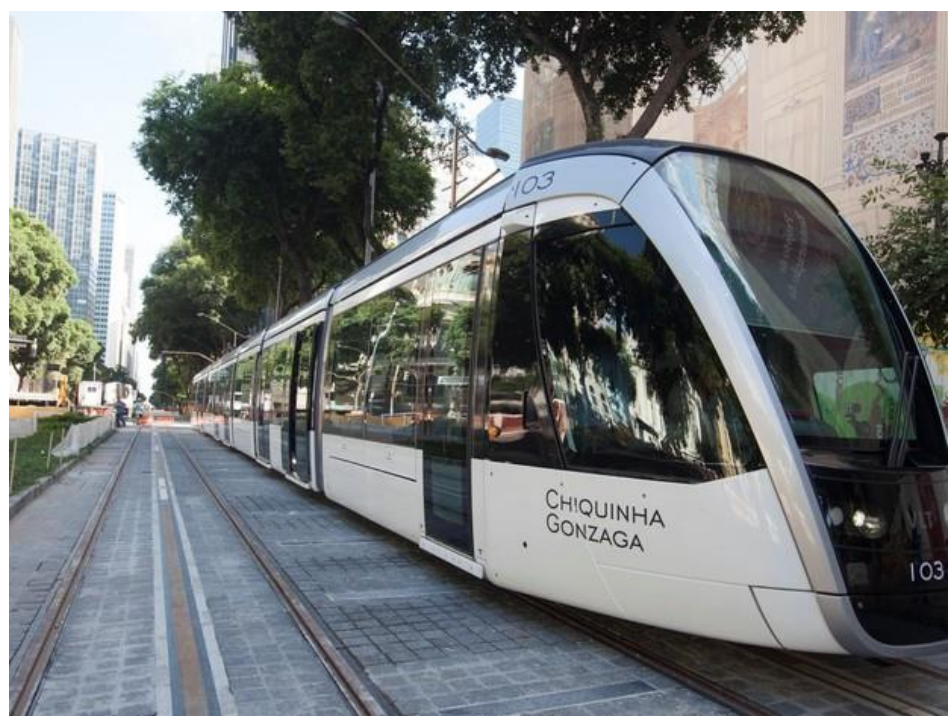

Fonte: g1.globo.com (2017)

\section{BUS RAPID TRANSIT (BRT)}

O BRT (Bus Rapid Transit) é um ônibus que opera em uma via segregada, exclusiva, e o embarque e desembarque é em nível na plataforma. Além disso, apresenta velocidade comercial elevada, o pagamento da passagem é antecipado e há informações aos usuários através da central de controle operacional. Atualmente, as cidades que utilizam esse sistema de transporte são Curitiba, Goiânia e Uberlândia. Infelizmente, essas linhas ainda utilizam o transporte movido a diesel, mas algumas empresas como a Marcopolo já disponibilizam para venda o BRT híbrido, que utiliza biodiesel e eletricidade.

Há exemplo de veículos híbridos em funcionamento. A cidade de Curitiba colocou em funcionamento em março de 2016 uma linha exclusiva desses veículos, e, em 2014, a cidade de Bogotá incorporou em sua frota 200 BRTs híbridos.

Figura 2 - BRT híbrido apresentado em 2013 pela empresa Marcopolo

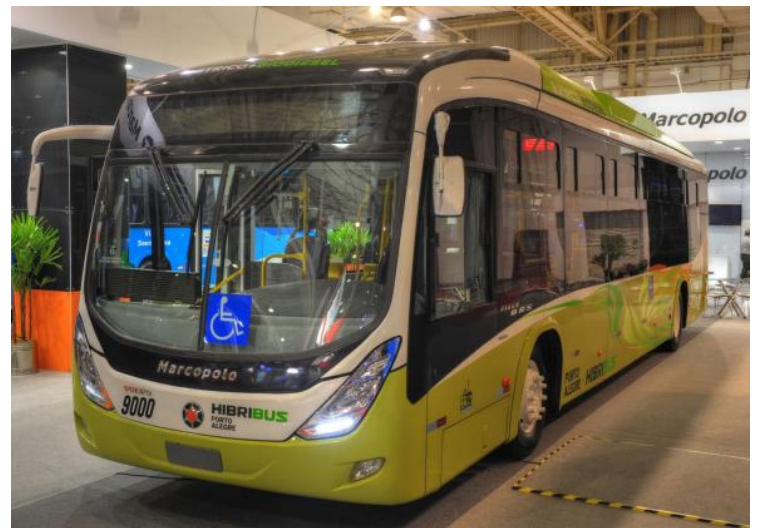

Fonte: Marcopolo.com.br (2017) 


\section{BONDES}

O primeiro bonde do Brasil surgiu em 1892 e logo se transformou no meio de transporte dominante no país. Existiam até carros específicos para desempenhar alguns serviços, como o transporte de enfermos, carros mortuários e para casamentos e batizados.

Atualmente, uma das únicas cidades do Brasil a permanecer com os bondes urbanos é a cidade de Campos de Jordão - SP, e o serviço destina-se quase exclusivamente ao turismo. Os bondes ainda fazem parte da realidade de algumas cidades como Estocolmo, Suécia; Melbourne, Austrália; Nova Orleans, EUA; Hong Kong; Istambul, Turquia; Amsterdã, Holanda; Praga, República Tcheca; Budapeste, Hungria; São Francisco, EUA; Lisboa, Portugal. Deve-se lembrar de que o bonde urbano teve um papel importante na criação do VLT.

Figura 3 - Bonde circulando pela cidade de Campos do Jordão - SP

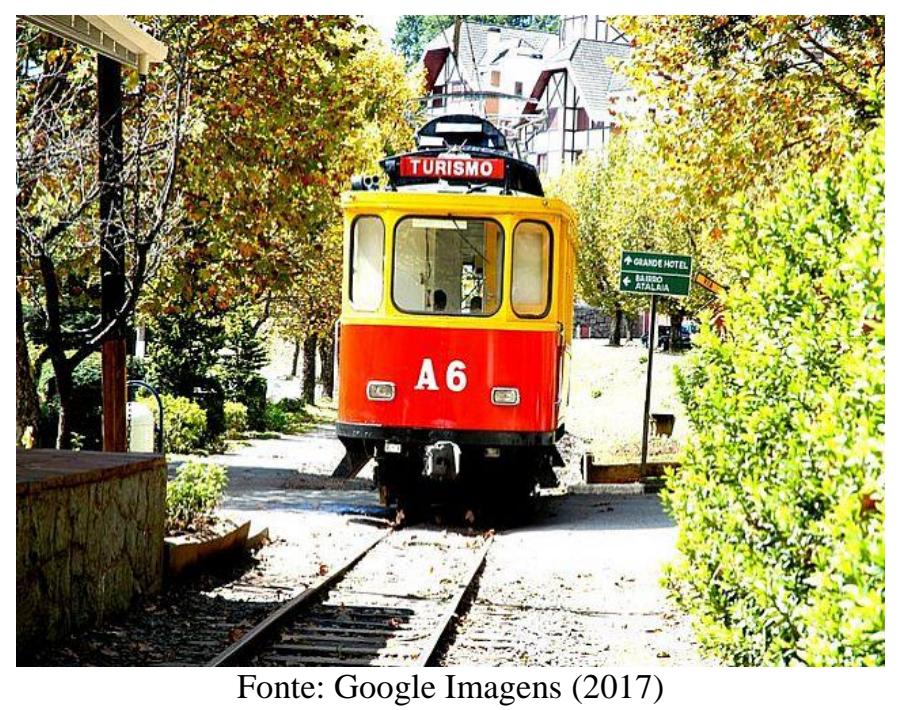

\section{TELEFÉRICOS E BONDINHOS AÉREOS}

Os teleféricos e bondinhos aéreos são usados principalmente para o transporte de pessoas em visita a locais turísticos. Mundialmente são os Bondinhos do Pão de Açúcar, situado na cidade do Rio de Janeiro se destacam pelo uso turístico. Os Bondinhos do Pão de Açúcar rolam

ao longo de dois cabos-trilho de aço, fixos nas estações, com $50 \mathrm{~mm}$ de diâmetro cada, constituídos por 192 fios de aço enrolados e são tracionados por um cabo de tração de $24 \mathrm{~mm}$ de diâmetro. O movimento é gerado na estação Motriz por um motor elétrico (bondinho.com.br).

Outras cidades que usam bondinhos aéreos e teleféricos como opções turísticas são 
Balneário Camboriú - SC, Nova Trento - SC, Canela - RS e Aparecida - SP.

Figura 4 - Bondinho trafegando num ponto turístico de Canela

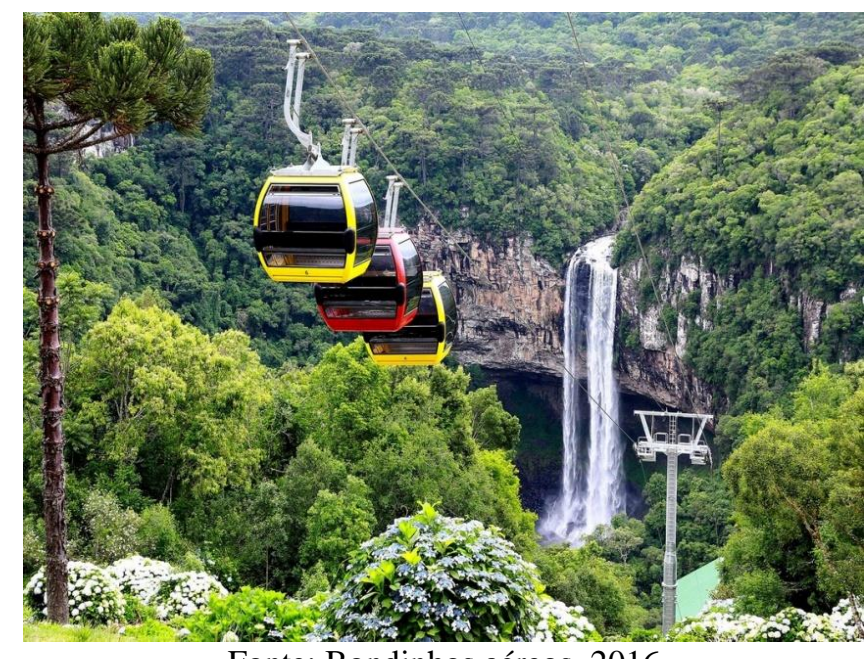

Fonte: Bondinhos aéreos, 2016

\section{BICICLETAS}

Como não falar do principal meio de transporte sustentável utilizado na atualidade? É uma das principais escolhas na hora de se locomover a pequenas e médias distâncias, além de ser uma opção saudável ao meio ambiente e ao usuário, pois incentiva à prática de esportes. Outra opção atual são as bicicletas elétricas, tendo maior autonomia, praticidade e velocidade de até $30 \mathrm{~km} / \mathrm{h}$, e algumas possuem até a opção de serem dobráveis para facilitar o transporte. Além disso, claro, são recarregáveis em tomadas convencionais. Temos no mercado a opção de bicicletas sem motor dobráveis que garantem maior praticidade ao carregá-las.

\section{METRÔ}

Outro meio de transporte que é exemplo de sustentabilidade é o metrô. Além de ser um transporte limpo, transporta passageiros em massa e dá garantia de agilidade, rapidez, segurança e conforto. É uma das principais soluções dos grandes centros urbanos. Além do sistema convencional elétrico, vem surgindo a demanda de movê-los a energia solar. Um pioneiro nesse sistema é a cidade de Milão, que, ao implementar a energia solar como principal fonte para o metrô, reduziu os gastos e as emissões gases de combustíveis fósseis no ambiente.

\section{OUTROS TRANSPORTES ELÉTRICOS}

Nos tempos atuais, vêm surgindo diversos meios de locomoção à base de eletricidade.

Temos, por exemplo, a scooter elétrica: 
Figura 5 - Scooter elétrica

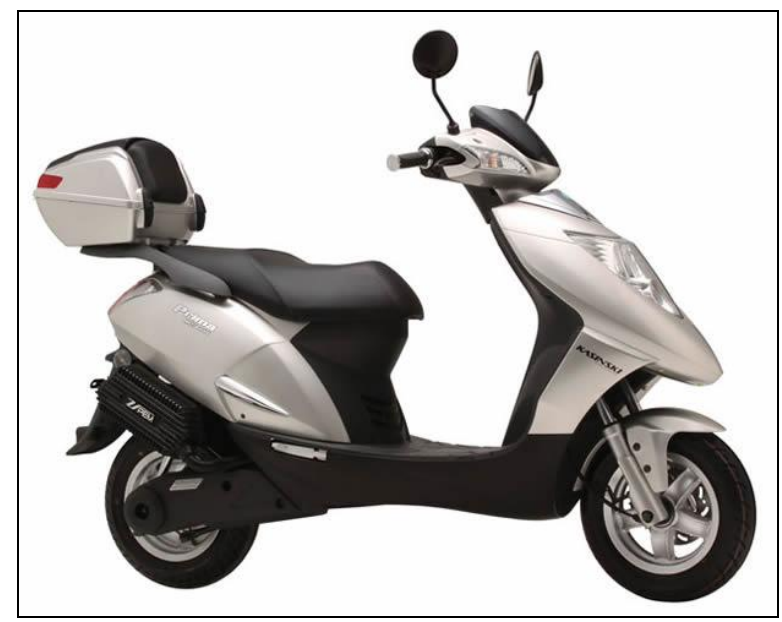

Fonte: Google Imagens (2017)

E há também o carro elétrico:

Figura 4 - Carro elétrico da BMW

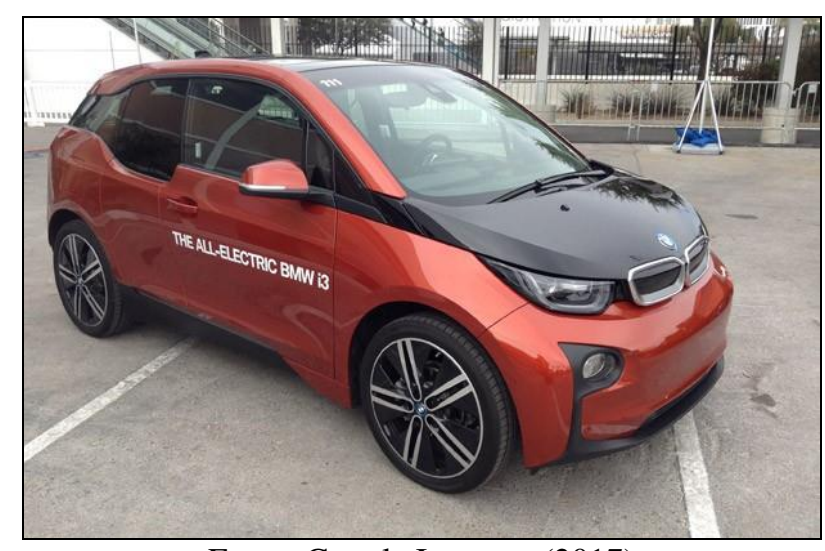

Fonte: Google Imagens (2017)

SKATE

O skate existe desde os anos 1960, sendo até hoje visto com certo preconceito em algumas cidades e uma das causas dos transtornos na circulação de pedestres. Entretanto, o problema real é a falta de espaços para que todos os modais e os pedestres usem o espaço com harmonia.

A mobilidade com skate traz muitas vantagens: rapidez ao se locomover a distâncias curtas e médias, melhora o meio ambiente, não ocupa espaço, pois o usuário o carrega, é possível integrá-lo a outros modais de transporte e oferece uma atividade física.

Uma pesquisa do Datafolha mostrou que, na cidade de São Paulo, há mais de 400 mil praticantes de skates, e, neste momento em que buscamos sustentabilidade na mobilidade urbana, o skate se torna uma ótima opção. Fernando Haddad quando prefeito de São Paulo em 2016 afirmou em entrevista a XYZ Live que a cultura precisa ser mudada: "nossa sociedade 
está envelhecendo e não precisamos perder saúde. E aí que a questão do esporte, associada à mobilidade, é fundamental, pois a pessoa pode ir ao trabalho se exercitando".

Figura 7 - Skate como opção de mobilidade urbana

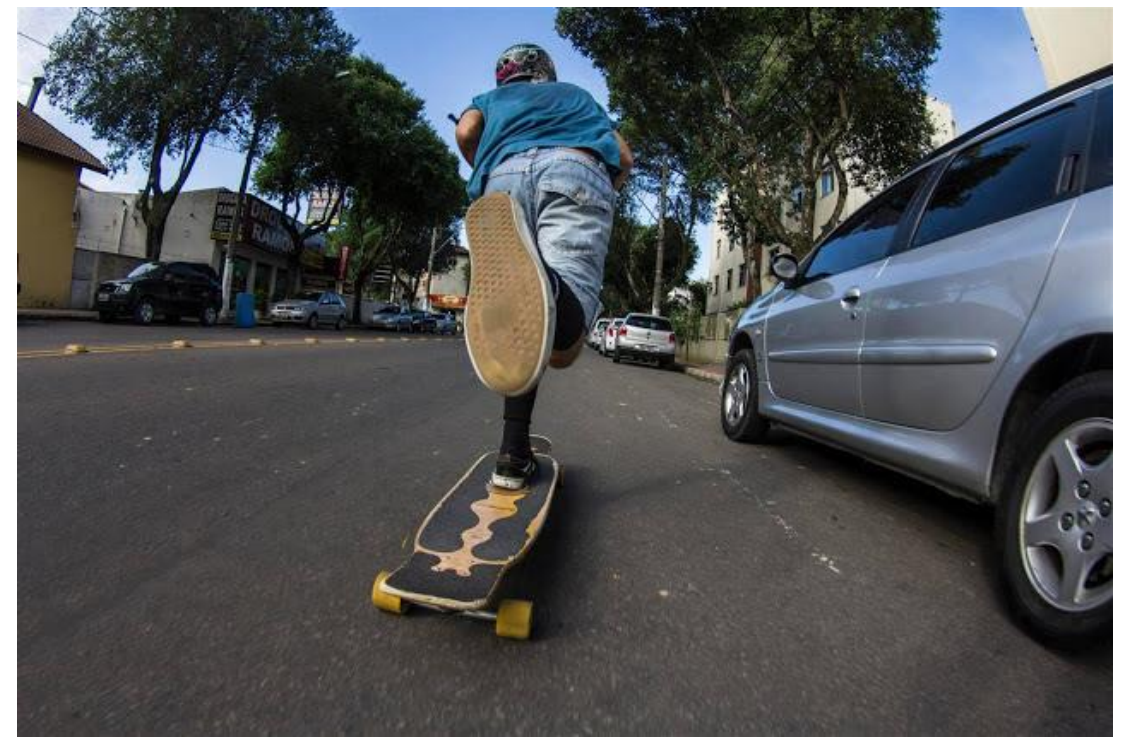

Fonte: euamolongboard.com (2017)

\section{TREM ALIMENTADO POR HIDROGÊNIO}

A Alemanha está se preparando para introduzir em sua mobilidade urbana o trem que tem zero emissões, CoradiaiLint, que só emite vapor, oferecendo alternativa aos trens movidos a diesel. O trem tem previsão de ser aberto ao público em dezembro de 2017. A energia do hidrogênio funciona quando o hidrogênio é queimado com oxigênio para produzir grandes quantidades de energia, com o único subproduto sendo água.

Figura 8 - Coradiailint

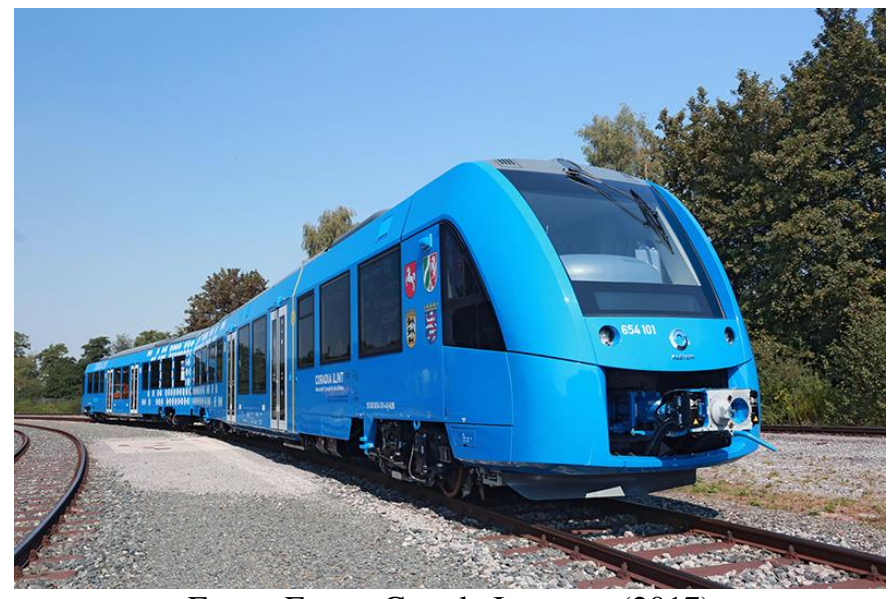

TRENS MAGNÉTICOS

Fonte: Fonte: Google Imagens (2017) 
A China está desenvolvendo um trem de levitação magnética que pode chegar a uma velocidade de $600 \mathrm{~km} / \mathrm{h}$.

Figura 9 - Exemplo de trens sendo desenvolvidos na China

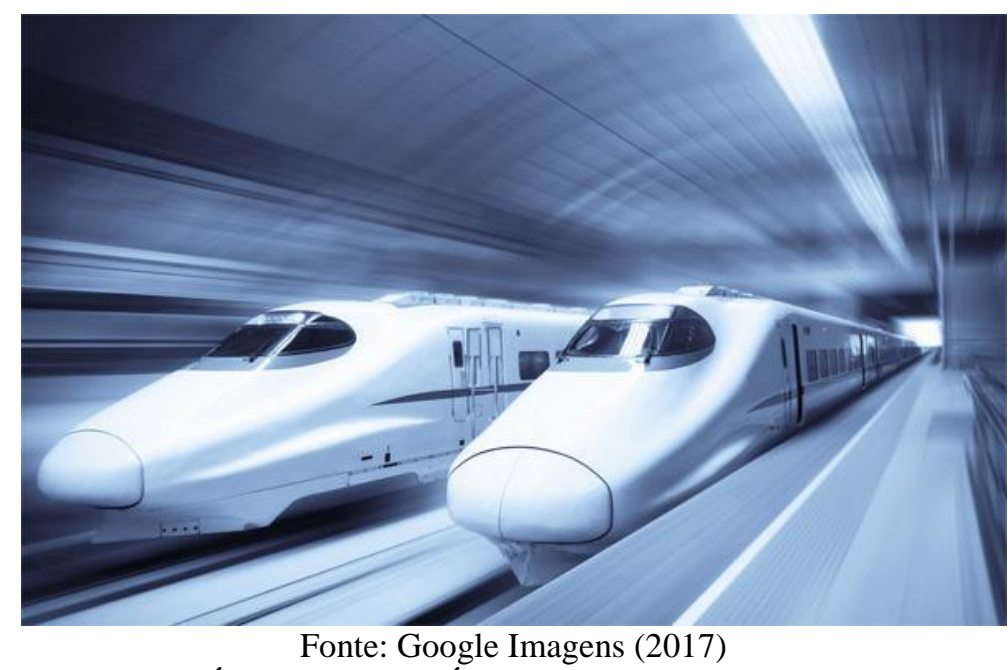

TRANSPORTE ULTRARRÁPIDO EM CÁPSULA

A empresa dinamarquesa BjarkeIngels Grupo (BIG) promete lançar um projeto em 7 de novembro, com o transporte ultrarrápido que irá ligar Abu Dhabi e Dubai, e sua travessia será feita em minutos. Essa opção será para pessoas e transporte de cargas.

Figura 10 - Hiperloop - a cápsula ultrarrápida

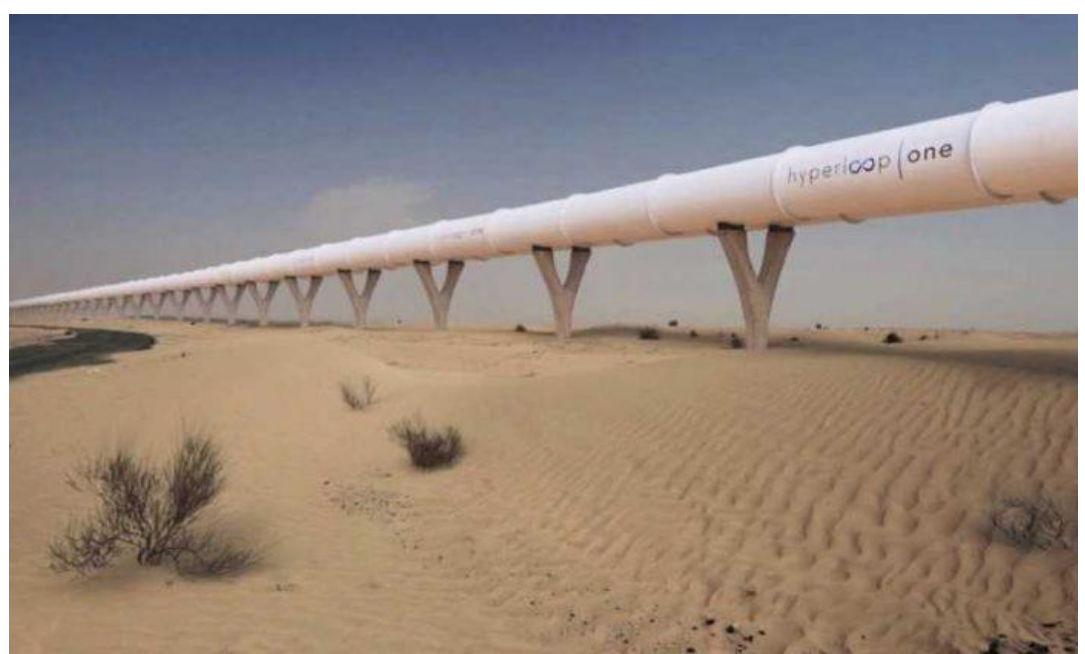

Fonte: Google Imagens (2017)

\section{ALGUMAS SOLUÇÕES PARA MELHORAR A MOBILIDADE URBANA}

Além de trocar a opção de veículos motorizados por meios de transporte mais sustentáveis, o governo, principalmente os municipais, devem avaliar a melhor maneira de melhorar mobilidade. 
Seguem algumas soluções para se ter uma mobilidade urbana eficiente e conscientizar a população:

a) transporte público decente com horários pontuais e vias exclusivas para circulação, além da climatização dos ônibus, treinamento dos funcionários para que eles sejam educados com os passageiros e melhora dos preços das passagens;

b) Pedágio urbano para carros. A ideia é quem usa com mais frequência o carro pagar mais do que aquele que anda menos. A cidade de Londres utiliza esse sistema desde 2003. Qualquer carro que queira entrar no centro da cidade precisa pagar o pedágio. Isso diminui os congestionamentos e incentiva o uso do transporte coletivo;

c) Investimento em transporte cicloviário. Não adianta somente a cidade querer que a população use bicicletas, mas deve oferecer segurança e infraestrutura.

d) rodízio de veículos. A cidade de São Paulo adotou esse sistema, o qual tem dado bons resultados. $\mathrm{O}$ site IG explica como funciona:

O rodízio é uma operação feita pela CET (Companhia de Engenharia de Tráfego) no centro expandido de São Paulo. De acordo com o final de placa e dia da semana, os veículos não poderão circular em ruas e avenidas da região das $7 \mathrm{~h}$ às $10 \mathrm{~h}$ e das $17 \mathrm{~h}$ às 20h. Nos horários de pico, os automóveis não podem circular na área que compreende as vias dentro de um anel viário criado pela CET. Os carros com placa com final 1 e 2 não podem circular por essa região (veja no mapa abaixo) às segundas-feiras, enquanto os finais 3 e 4 estão proibidos de transitar às terças. Motoristas cuja placa do automóvel termine em 5 e 6 não podem dirigir às quartas; finais 7 e 8 estão proibidos às quintas e, às sextas-feiras, finais 9 e 0 . Todos os carros e caminhões que circulam por São Paulo estão sujeitos ao rodízio, inclusive aqueles com placas de outros municípios. As motocicletas não participam do rodízio. $\mathrm{O}$ motorista que for pego circulando pelo centro expandido com um veículo que estaria impedido pelo rodízio pode ser multado. A infração é de nível médio e dá quatro pontos na CNH, além de uma multa de R\$ 85,13 (IG São Paulo, 2016).

e) remoção de obstáculos;

f) investimentos em transportes alternativos, como os citados acima;

g) central de inteligência para o trânsito;

h) adoção de horários alternativos para se começar e terminar de trabalhar, evitando o fluxo maior e intenso de trânsito;

i) mais multas e fiscalização;

j) diminuição do status de se ter um carro próprio, visto que hoje há uma necessidade de ter um carro como status na sociedade.

\section{EXEMPLOS DE MOBILIDADE E SUSTENTABILIDADE URBANA}




\section{COMO ANDAR SEM CARRO EM SÃO PAULO}

O projeto "Como viver sem carro em São Paulo" criou um aplicativo para se ter uma opção de não utilização do carro. A proposta do Sem Carro - São Paulo é ajudar os usuários a calcular de maneira rápida e prática a rota, o tempo e o custo de cada meio de transporte diferente ou da combinação de vários deles. O sistema de georreferenciamento do aparelho encontra a localização do usuário, se essa for a sua origem, e, ao digitar o destino, oferece as melhores rotas e define o tempo de viagem para cada opção de modal. Para os transportes pagos (metrô, CPTM ou táxi), ele apresenta o custo preciso, segundo informa o desenvolvedor.

\section{SOROCABA}

Sorocaba está desenvolvendo ações de mobilidade urbana que levam em consideração a sustentabilidade. Ações como implantação de corredores para o sistema BRT (Bus Rapid Transit), pacotes de obras viárias, construção de ciclovias, melhoria na acessibilidade de pedestres e o Projeto Integra Bike fizeram a cidade se destacar como exemplo na área de mobilidade urbana sustentável.

\section{MARICÁ, RJ}

A cidade de Maricá no estado do Rio de Janeiro decidiu investir no transporte coletivo público. Com base na lei do direito de ir e vir do cidadão, a cidade implantou o passe livre. As primeiras linhas começaram a circular em 2014, e as catracas existem somente para calcular a quantidade de passageiros.

Figura 11 - Ônibus "Vermelhinho" de Maricá, RJ

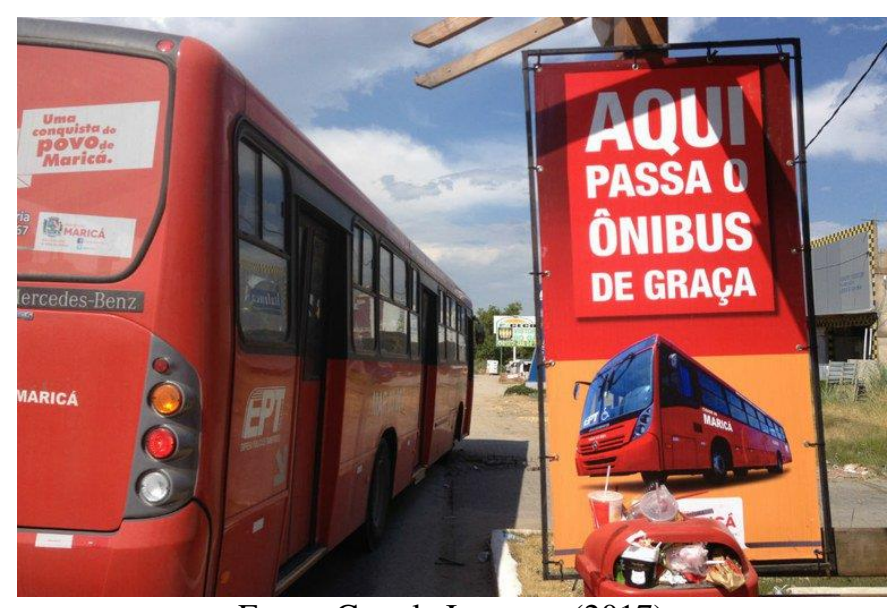

Fonte: Google Imagens (2017)

\section{MILÃO}


A M1 (linha vermelha) do metrô de Milão é alimentada com energia solar. Além de economizar dinheiro, esse projeto tem reduzido muito as emissões de $\mathrm{CO} 2$.

Figura 12 - Linha de metrô alimentada por energia solar

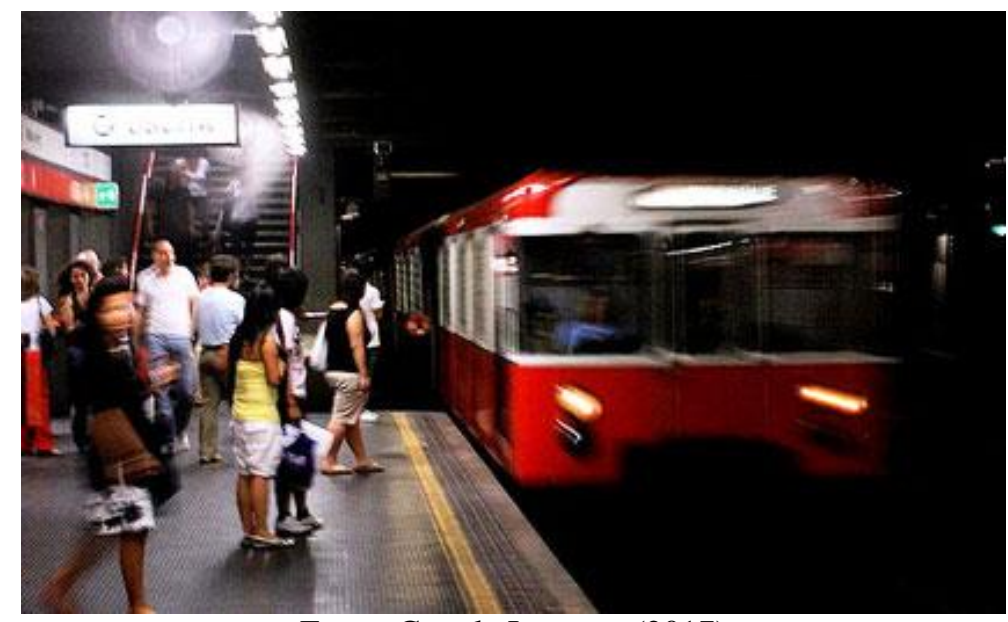

Fonte: Google Imagens (2017)

\section{RESULTADOS DA PESQUISA DE CAMPO}

Foi realizada uma pesquisa via internet para que pessoas de diversos municípios respondessem a perguntas sobre o seu transporte diário e a possibilidade de integração desses transportes nas suas rotinas. Segue a lista de perguntas que foram disponibilizadas.

1. Que tipo de transporte você mais usa para se locomover no seu dia a dia?

2. Você utiliza algum meio de transporte sustentável?

3. Qual meio de transporte sustentável você utiliza?

4. Qual dificuldade você encontra ao utilizar transporte não motorizado ou a pé?

5. Na sua cidade, existe infraestrutura para a utilização de meios de transporte alternativos?

6. Existe a possibilidade de utilização de meios de transportes sustentáveis na sua rotina diária?

7. Se sua cidade oferecesse recursos para utilizar meios não motorizados, você usaria? Se sim, quais?

8. Você se preocupa com a emissão de $\mathrm{CO} 2$ e o aquecimento global por causa da descontrolada utilização de veículos?

9. Dê alguma sugestão para melhorar a utilização de meios de transporte sustentáveis na sua cidade.

Um total de 49 pessoas responderam às perguntas acima. Seguem os resultados: 
Gráfico 1 - Tipos de veículos utlizados

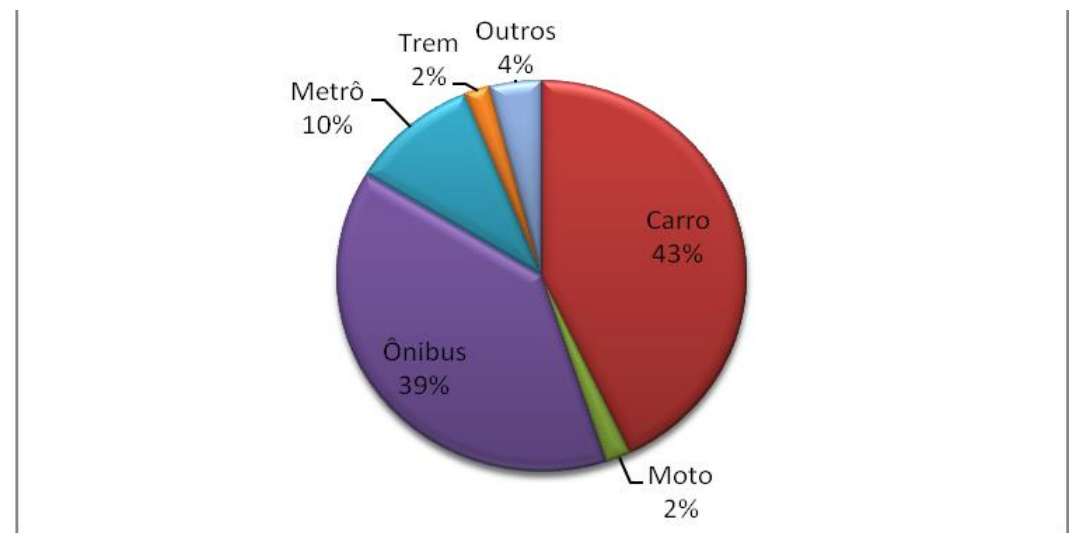

Fonte: Elaborado pelas autoras, 2016

Gráfico 2 - Meio de transporte sustentável

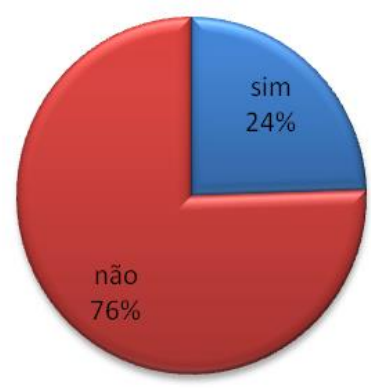

Fonte: Elaborado pelas autoras, 2016

Gráfico 3 - Quais meios de transportes são utilizados

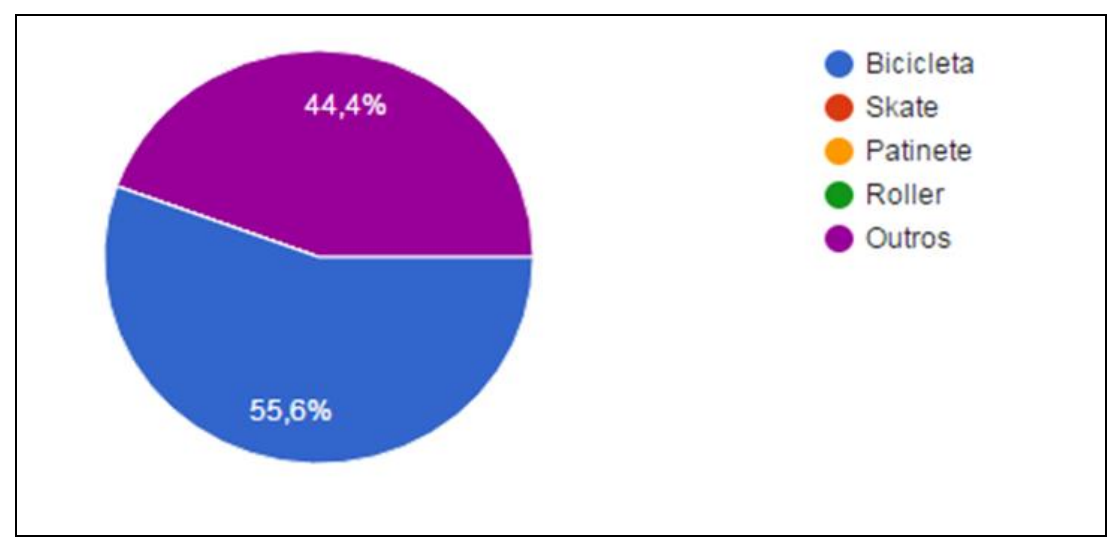

Fonte: Elaborado pelas autoras, 2016

Gráfico 4 - Cidades com infraestrutura para transportes alternativos 


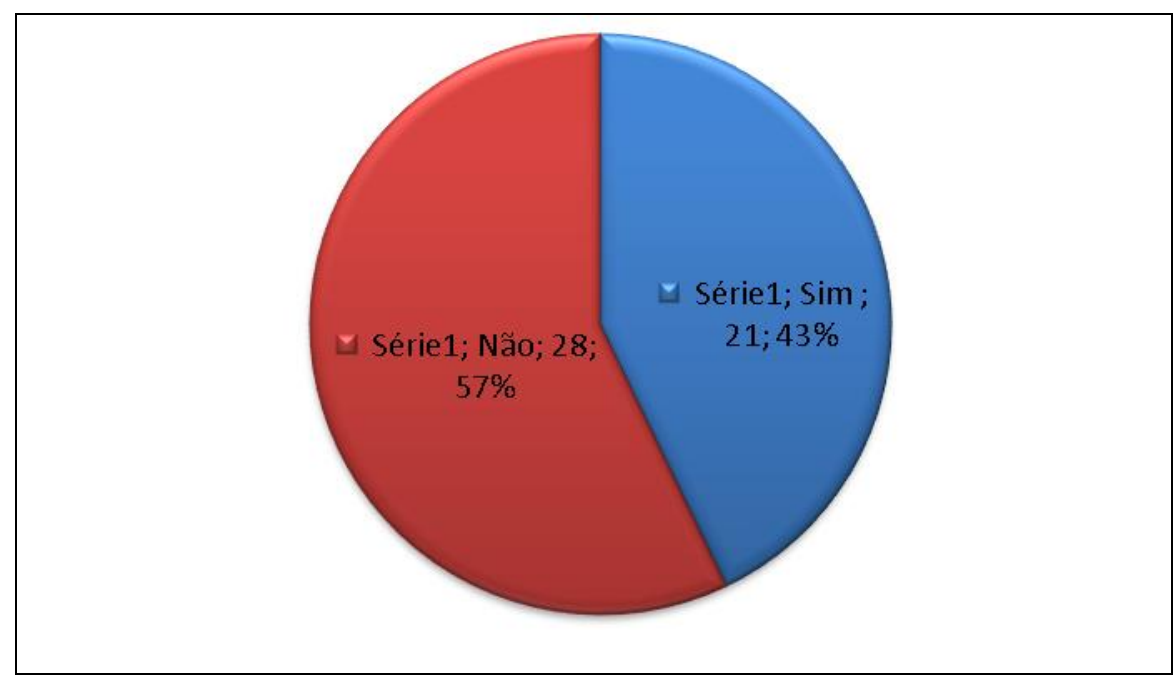

Fonte: Elaborado pelas autoras (2017)

Gráfico 5 - Preocupação dos entrevistados com a poluição dos meios de transportes

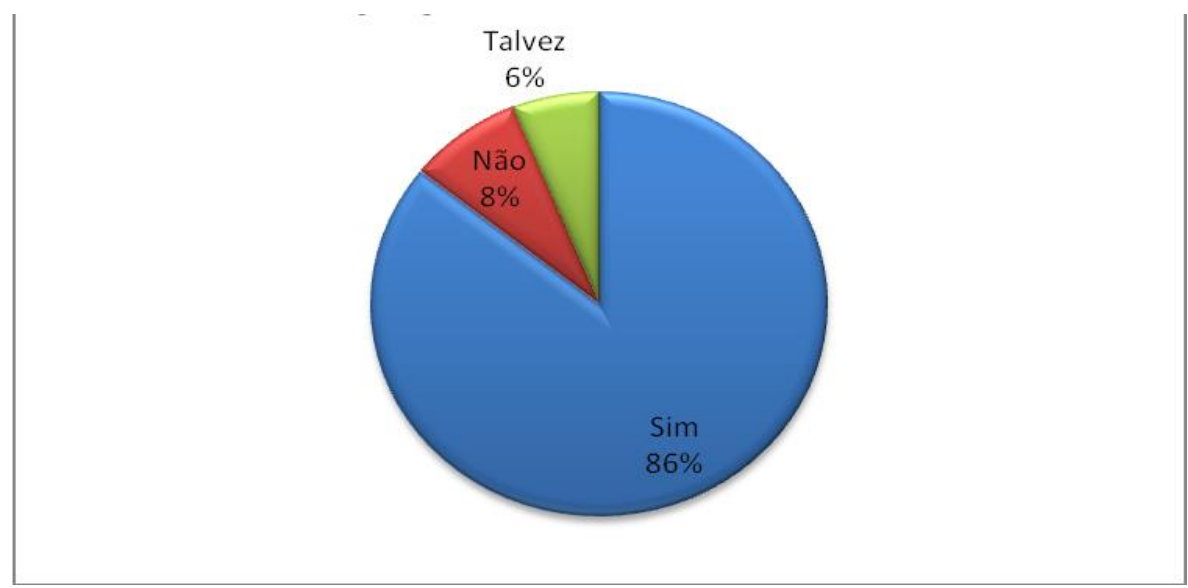

Fonte: Elaborado pelas autoras (2017)

\section{CONCLUSÃO}

De acordo com pesquisas acerca do assunto sustentabilidade para mobilidade urbana e a pesquisa feita pelo grupo, podemos dizer que esse é um assunto complexo, que envolve pessoas, governos, investimentos etc. Não é somente com conscientização, programas e projetos que o mundo mudará de repente os hábitos.

Em nossa pesquisa, os participantes relataram dificuldades de usar um transporte alternativo, e, dentre as dificuldades, listamos:

a) falta de infraestrutura;

b) falta de manutenção das vias;

c) inexistência de faixas exclusivas para veículos não motorizados; 
d) falta de educação no trânsito;

e) problemas de segurança pública;

f) relevo acidentado.

Há realmente pessoas interessadas e dispostas a mudar seus hábitos por um ambiente mais saudável. Mas, infelizmente, faltam projetos e incentivos para melhorar a rotina dos grandes centros urbanos. Em algumas respostas, percebemos que a cidade dispõe de acesso, mas peca na segurança pública, sendo que muitos responderam que têm medo que andar com veículos não motorizados e serem vítimas de assalto ou violência.

Ainda temos muito para evoluir, principalmente no Brasil, mas há diversos exemplos a serem seguidos em relação à mobilidade sustentável, como Amsterdã e Barcelona. Finalizamos este trabalho com uma frase de Enrique Peñalosa: "Uma boa cidade não é aquela em que até os pobres andam de carro, mas aquela em que até os ricos usam transporte público"1.

\section{REFERÊNCIAS}

25 ALTERNATIVAS para a melhoria da mobilidade urbana. Disponível em: $<$ https://meiaum.wordpress.com/2013/10/08/25-alternativas-para-a-melhoria-da-mobilidadeurbana/>. Acesso em: 6 nov. 2016

BAHIA. Metrô é exemplo de desenvolvimento e sustentabilidade. Disponível em: <http://www.sedur.ba.gov.br/2016/06/847/Metro-e-exemplo-de-desenvolvimento-e-

sustentabilidade.html>. Acesso em: 06 nov. 2016

CINCO dicas que você precisa saber sobre o rodízio em São Paulo. Disponível em: $<$ http://ultimosegundo.ig.com.br/igvigilante/transito/2016-05-31/cinco-dicas-que-voceprecisa-saber-sobre-o-rodizio-em-sao-paulo.html>. Acesso em: 06 nov. 2016.

EMPRESA MARCOPOLO. Ônibus viale BRS com tração híbrida e BRT são destaques da Marcopolo na Transpúblico, 2013. Disponível em: <http://www.marcopolo.com.br/marcopolo_sa/pt/noticias/detalhes/2013-07-

04/onibus_viale_brs_com_tracao_hibrida_e_brt_sao_destaques_da_marcopolo_na_transpubli co_2013>. Acesso em: 6 nov. 2016.

FREIRE, Mariana. A solução para o trânsito que vem dos não motorizados. Disponível em:

<http://www.opovo.com.br/app/opovo/cotidiano/2015/03/03/noticiasjornalcotidiano,3401067/ a-solucao-para-o-transito-que-vem-dos-nao-motorizados.shtml>. Acesso em: 6 nov. 2016.

INSTITUTO RUA VIVA. Mobilidade Sustentável: Sua Rua. Disponível em: <http://www.ruaviva.org.br/mobilidade-sustentavel.html>. Acesso em: 6 nov. 2016.

SIEMENS. Mobilidade: Transporte urbano eficiente em megacidades. Disponível em: <http://www.siemens.com.br/desenvolvimento-sustentado-em-megacidades/mobilidade.html> Acesso em: 6 nov. 2016.

\footnotetext{
${ }^{1}$ http://www.frasesdereflexao.net/frase/ricos-usam-transporte-publico - Acesso 18/0//2017. Enrique Peñalosa foi prefeito de Bogotá entre 1998 e 2001.
} 
SILVEIRA, Daniel. Skate e patins são alternativas para mobilidade na cidade. Disponível em: <http://www.ibahia.com/detalhe/noticia/skate-e-patins-sao-alternativas-para-mobilidadena-cidade/?cHash=1b6551ed789c3a424ea297a17250d619> Acesso em: 6 nov. 2016.

VOGEL, Jaison. Hyperloop: o meio de transporte mais rápido do mundo. Disponível em: <http://oglobo.globo.com/economia/carros/hyperloop-meio-de-transporte-mais-rapido-domundo-19325590>. Acesso em: 6 nov. 2016. 